\title{
Interactive comment on "Case study of spatial and temporal variability of snow cover, grain size, albedo and radiative forcing in the Sierra Nevada and Rocky Mountain snowpack derived from imaging spectroscopy" by F. C. Seidel et al.
}

F. C. Seidel et al.

felix.seidel@jpl.nasa.gov

Received and published: 12 April 2016

Please find our replies to the comments of both reviewers and the manuscript with highlighted changes, which we propose for the final version, in the attached supplement.

Please also note the supplement to this comment: 